\title{
Analyzing the Quality Gapsin the Services of Rehabilitation Centers Using the SERVQUAL Technique in Ahvaz, Iran
}

\author{
Amin Torabipour, Rezvan Sayaf, ${ }^{2, *}$ Reza Salehi, ${ }^{2}$ and Roya Ghasemzadeh ${ }^{2}$ \\ ${ }_{1}^{1}$ Department of Health Services Management, School of Public Health, Ahvaz Jundishapur University of Medical Sciences, Ahvaz, IR Iran \\ ${ }^{2}$ Musculoskeletal Rehabilitation Research Center, Ahvaz Jundishapur University of Medical Sciences, Ahvaz, IR Iran \\ ${ }^{*}$ Corresponding author: Rezvan Sayaf, Musculoskeletal Rehabilitation Research Center, Ahvaz Jundishapur University of Medical Sciences, Ahvaz, IR Iran. Tel: +98-6135587857, Fax: \\ 98-6132931721, E-mail: rezvan.sayaf@gmail.com
}

Received 2015 August 19; Revised 2015 October 31; Accepted 2015 November 3.

\begin{abstract}
Background:The SERVQUAL(service quality) technique is one of the best techniques to evaluate customers' expectations and perceptions of the quality of the services they have received.

Objectives: This study aimed to assess the quality gap in the services provided by rehabilitation centers in Iran using the SERVQUAL technique.

Patients and Methods: This was a cross-sectional study conducted in Ahvaz, Iran. The study sample was composed of 255 patients randomly selected from 5 rehabilitation centers. The research data was collected using a valid questionnaire, consisting of 22 items and 5 dimensions of service quality.

Results: Most of the patients included in this study were female(72.9\%), and the mean age of the patients was $40 \pm 13.2$ years. The total mean scores of the patients' expectations and perceptions were 3.73 $(\mathrm{SD}=0.3)$ and $3.56(\mathrm{SD}=0.5)$, respectively. According to the gap analysis, there was a negative quality gap in each of the five SERVQUAL dimensions, but in the assurance dimension, this gap was very low, and not found to be significant. The quality gap was more negative in the tangiblesfactor $(-0.33)$ and reliability $(-0.30)$ than in the other factors.

Conclusions: There was a negative gap between the patients' expectations and what they actually perceived in the studied rehabilitation centers (with the exception of one public clinic); therefore, improvements are needed across all five dimensions.

Keywords: Quality of Helth Care, Rehabilitation Centers, Patient Satisfaction
\end{abstract}

\section{Background}

Improving the quality of service is an important strategy in today's competitive environment $(1,2)$. In addition, quality is a key determinant of the market share and organizational excellence $(1,3)$. Improving the quality of healthcare services reduces organizational costs and increases organizational productivity and performance $(3,4)$. Therefore, the improvement of service quality is an important challenge for healthcare providers (5).

Currently, the importance of the perspectives of patients, as consumers of healthcare services, is increasingly considered while measuring the quality of healthcare. For example, a patient's assessment of the healthcare services provided may reveal previously unknown quality problems (6). Nowadays, improving the quality of healthcare services is more important to managers and policymakers $(2,7)$. There is often a gap between the patient's needs and the managerial performance of medical and healthcare centers; therefore, understanding the expectations and perceptions of customers with regard to the quality of services can facilitate resource allocations and reduce the quality gap (2). Reducing the gaps between patients' expectations and perceptions of service quality leads to increases in patient satisfaction $(4,8)$.
Rehabilitation centers, which provide key paramedical and tertiary level services, increase the quality of life of disabled patients. In addition, the competition for quality rehabilitation services has been increasing, as a key element of the healthcare system (9-11).Overall, the quality of medical services reflects two components: technical and functional. Sincethe evaluation of the technical component (diagnostic and therapeutic processes) is difficult for patients, they are more likely to assess the functional services (services processes) (12).

The SERVQUAL technique, designed by Parasuraman et al. (13), is one of the best techniques for evaluating customers' expectations and perceptions of service quality $(1,2)$, and includes five dimensions: tangibles, reliability, responsibility, empathy, and assurance $(4,14)$. Curiand Sinkler (2002) showed that there was a gap in the quality of the studied rehabilitation centers, and highlighted reliability and empathy as important dimensions (13). The study conducted by Taner and Antony (2006) reported that patient satisfaction was higher in private hospitals than in public hospitals. They also showed that satisfaction with the physicians and the cost of services are the key determinants of service quality in public hospitals (15).

Copyright (C) 2016, Ahvaz Jundishapur University of Medical Sciences. This is an open-access article distributed under the terms of the Creative Commons Attribution-NonCommercial 4.0 International License (http://creativecommons.org/licenses/by-nc/4.0/) which permits copy and redistribute the material just in noncommercial usages, provided the original work is properly cited. 


\section{Objectives}

This study explored consumer satisfaction as an important indicator of quality in a rehabilitation setting. In order to do this, it was important to measure specific aspects of the rehabilitation services. A quality assessment of services is a basic requirement for a customer-focused performance management program, especially for medical services.

\section{Patients and Methods}

This cross-sectional study was conducted from April of 2014 until February of 2015,among 255 recipients of services, including physiotherapy, speech therapy, and occupational therapy. The research took place in two teaching hospitals, two rehabilitation clinics, and one public hospital affiliated with the Iranian oil company in Ahwaz (Khuzestan). The following sampling formula was used:

$$
Z=\frac{Z \frac{\alpha^{2}}{2} \times \delta^{2}}{d^{2}}
$$

These medical centers were selected based on the existence of at least two of the three rehabilitation services mentioned above. The patients were randomly selected, and the inclusion criteria required at least one prior visit to the center, and an age of over 18 years.

The data were collected using the SERVQUAL questionnaire $(5,8)$ and patient interviews, while the validity of the questionnaire was assessed by expert opinion. The alpha coefficient was determined to be $r=0.7$. The SERVQUAL questionnaire was made up of twenty-two parallel Likert scale items, measuring five dimensions of service quality, consisting of tangibles (4 items), reliability (5 items), responsiveness (4 items), assurance (4 items), and empathy (5 items).Each item consisted of a five-point Likert scale ranging from strongly disagree $=1$ to strongly agree $=5$. The independent variables in this study included the patient' sage, sex, number of referrals to rehabilitation centers, basic and complementary medical insurance, residence location, educational level, marital status, employment status, initial familiarity with the center, type of services required, and record of disability. This questionnaire was completed before and after the services were received. In the first phase, the service recipients were asked to express their expectations about the quality of services. In the second phase (after receiving services, on the same day), their perceptions of the quality of services (performance) were evaluated. Using the differences between the scores of the patients' expectations and perceptions, the quality gaps between the different rehabilitation services were calculated.

In this study, the significance level was 5\%, and the data was analyzed using SPSS 18.0 (SPSS Inc., Chicago, IL, USA). Descriptive statistics, a paired t-test, and an ANOVA were used to evaluate and analyze the data.

\subsection{Ethical Issues}

This study was approved by the Ethics Committee of Ahvaz Jundishapur University of Medical Sciences, code: ajums.1392.145.

\section{Results}

It can be seen in Table 1 that most of the patients were female $(72.9 \%)$, the mean age of the patients was $40 \pm 13.2$ years, and $80 \%$ were married. Most of the patients were covered by the Social Security Insurance fund (43.9\%), while $27.5 \%$ of the patients had complementary medical insurance. The average number of visits per year was $20.17 \pm 19.2$, and $49.8 \%$ of the patients had chosen the rehabilitation center on the advice of their physicians.

\begin{tabular}{|c|c|}
\hline Variable & Values \\
\hline \multicolumn{2}{|l|}{ Gender } \\
\hline Male & $69(27.1)$ \\
\hline Female & $186(72.9)$ \\
\hline \multicolumn{2}{|l|}{ Age, $y$} \\
\hline$\leq 20$ & $5(2)$ \\
\hline $21-30$ & $73(28.6)$ \\
\hline $31-40$ & $59(23.1)$ \\
\hline $41-50$ & $55(21.6)$ \\
\hline $51-60$ & $41(16.1)$ \\
\hline$>60$ & $22(8.6)$ \\
\hline \multicolumn{2}{|l|}{ Residence } \\
\hline Ahvaz & $232(91)$ \\
\hline Other cities & $23(9)$ \\
\hline \multicolumn{2}{|l|}{ Marital status } \\
\hline Single & $40(15.7)$ \\
\hline Married & $204(80)$ \\
\hline Divorced & $11(4.3)$ \\
\hline \multicolumn{2}{|l|}{ Educational level } \\
\hline Illiterate & $13(5.1)$ \\
\hline Primary and secondary school & $188(73.8)$ \\
\hline Academic degree & $54(21.1)$ \\
\hline \multicolumn{2}{|l|}{ Medical insurance } \\
\hline Social security & $112(43.9)$ \\
\hline Medical services & $43(16.9)$ \\
\hline Military medical insurance & $4(1.6)$ \\
\hline Others & $96(37.6)$ \\
\hline \multicolumn{2}{|l|}{ Referral source } \\
\hline Physicians & $39(15.3)$ \\
\hline Friends and family & $127(49.8)$ \\
\hline Poster and mass media & $19(7.5)$ \\
\hline Other institutions & $58(22.7)$ \\
\hline Others & $12(4.7)$ \\
\hline \multicolumn{2}{|l|}{ Number of visits, per year } \\
\hline$\leq 10$ & $169(66.3)$ \\
\hline $11-20$ & $32(12.5)$ \\
\hline $21-30$ & $21(8.2)$ \\
\hline $31-40$ & $9(3.5)$ \\
\hline$>40$ & $24(9.4)$ \\
\hline \multicolumn{2}{|l|}{ Type of service } \\
\hline Physical therapy & $151(59.2)$ \\
\hline Speech therapy & $42(16.5)$ \\
\hline Occupational therapy & $62(24.3)$ \\
\hline
\end{tabular}


The majority of the patients were in Ahvaz city (91\%). Overall, $59.2 \%$ of the patients received physiotherapy services, $16.5 \%$ received speech therapy services, and $24.3 \%$ received occupational therapy services. In addition, $73.8 \%$ of the patients had completed primary and secondary school.

According to Table 2, the patients' expectations with regard to the dimensions were: tangibles $=3.76$, reliability $=$ 3.74 , responsibility $=3.77$, assurance $=3.71$, and empathy $=$ 3.68. The patients' perceptions were: tangibles $=3.43$, reliability $=3.44$, responsibility $=3.65$, and empathy $=3.60$. Based on the gap analysis of the dimensions, the quality gap was more negative in the tangible factors (-0.33) and reliability $(-0.30)$ than in the other factors. This study showed that the patients' expectations of the quality of services (3.73) were higher than their perceptions (3.56) and, generally, that the quality of services provided at the studied centers was lower than the patients' expectations. In Figure 1, the results of the analysis of the quality gapsin theservices in the studied hospitals and centers have been illustrated. According to the chart, there was no gap in the "E"medical center (gap was positive); but in all of the other centers and hospitals, the quality of the reha- bilitation services was lower. In the public and teaching hospital "A", the quality gap was higher (negative) than in the other studied hospitals.

As seen in Table 3, in item 1 "Employees are neat in appearance" and item 12 "Personnel are always willing to help," there were no quality gaps, and the differences between the perceptions and expectations of the patients were zero. In item 13 "Personnel are never too busy to respond to requests," item 16 "Personnel are consistently courteous,"

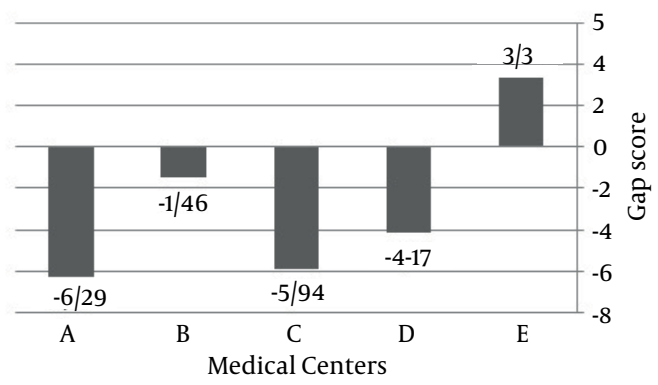

Figure 1. Quality Gaps in the Rehabilitation Services in the Studied Medical Centers

\begin{tabular}{|c|c|c|c|c|}
\hline Dimension & Expectation & Perception & Quality Gap (P-E) & PValue \\
\hline Tangibles $^{\mathrm{b}}$ & $3.76 \pm 0.39$ & $3.43 \pm 1.66$ & -0.33 & .002 \\
\hline Reliability $^{\mathrm{b}}$ & $3.74 \pm 0.46$ & $3.44 \pm 0.59$ & -0.30 & .001 \\
\hline Responsibility $^{\mathrm{b}}$ & $3.77 \pm 0.43$ & $3.65 \pm 0.60$ & -0.12 & .007 \\
\hline Assurance & $3.71 \pm 0.46$ & $3.69 \pm 0.52$ & -0.02 & .492 \\
\hline Empathy $^{b}$ & $3.68 \pm 0.47$ & $3.60 \pm 0.58$ & -0.08 & .019 \\
\hline Total $^{\mathrm{b}}$ & $3.73 \pm 0.35$ & $3.56 \pm 0.55$ & -0.17 & .001 \\
\hline
\end{tabular}

${ }^{\mathrm{a}}$ Data are presented as mean $\pm \mathrm{SD}$.

$\mathrm{b}_{\text {significant. }}$

\begin{tabular}{|c|c|c|c|c|c|}
\hline Dimension & Item & Expectation & Perception & Quality Gap (P-E) & PValue \\
\hline \multirow[t]{4}{*}{ Tangibles } & Employees are neat in appearance & $3.75 \pm 0.434$ & $3.75 \pm 0.463$ & 0.00 & .914 \\
\hline & Physical facilities are visually appealing ${ }^{\mathrm{b}}$ & $3.78 \pm 0.415$ & $3.40 \pm 0.854$ & -0.38 & .000 \\
\hline & The department has up-to-date equipment ${ }^{\mathrm{b}}$ & $3.75 \pm 0.443$ & $2.26 \pm 1.145$ & -0.49 & .000 \\
\hline & Physical facilities in accordance with service ${ }^{b}$ & $3.76 \pm 0.434$ & $3.98 \pm 0.970$ & -0.78 & .000 \\
\hline \multirow[t]{5}{*}{ Reliability } & When something is promised, it is done ${ }^{\mathrm{b}}$ & $3.73 \pm 0.477$ & $3.55 \pm 0.806$ & -0.18 & .001 \\
\hline & Sincere interest shown in solving problems ${ }^{b}$ & $3.75 \pm 0.469$ & $3.58 \pm 0.809$ & -0.17 & .003 \\
\hline & Carrying outservices right the first time ${ }^{\mathrm{b}}$ & $3.75 \pm 0.471$ & $3.56 \pm 0.791$ & -0.19 & .001 \\
\hline & Provision of services in the time promised ${ }^{b}$ & $3.75 \pm 0.471$ & $3.30 \pm 1.118$ & -0.45 & .000 \\
\hline & Keeping client records correctly without mistakes ${ }^{\mathrm{b}}$ & $3.73 \pm 0.528$ & $3.37 \pm 0.921$ & -0.36 & .000 \\
\hline \multirow[t]{4}{*}{ Responsibility } & Information provided on when services will be performed ${ }^{b}$ & $3.79 \pm 0.435$ & $3.66 \pm 0.776$ & -0.13 & .013 \\
\hline & Provision of prompt service ${ }^{b}$ & $3.76 \pm 0.461$ & $3.55 \pm 0.867$ & -0.21 & .000 \\
\hline & Personnel are always willing to help & $3.76 \pm 0.463$ & $3.76 \pm 0.618$ & 0.00 & .929 \\
\hline & Personnel are never too busy to respond to requests & $3.76 \pm 0.477$ & $3.77 \pm 0.606$ & 0.01 & .931 \\
\hline \multirow[t]{4}{*}{ Assurance } & Behavior of the employees instills confidence in patients & $3.72 \pm 0.460$ & $3.67 \pm 0.734$ & -0.05 & .332 \\
\hline & Feeling of safety in interactions with employees & $3.70 \pm 0.515$ & $3.67 \pm 0.732$ & -0.03 & .596 \\
\hline & The personnel are consistently courteous ${ }^{\mathrm{b}}$ & $3.72 \pm 0.458$ & $3.80 \pm 0.520$ & 0.08 & .052 \\
\hline & Knowledgeable personnel to answer patients' questions & $3.73 \pm 0.454$ & $3.69 \pm 0.592$ & -0.04 & .297 \\
\hline \multirow[t]{5}{*}{ Empathy } & Provision of individual attention ${ }^{\mathrm{b}}$ & $3.69 \pm 0.543$ & $3.51 \pm 0.869$ & -0.18 & .002 \\
\hline & Convenient operating hours ${ }^{\mathrm{b}}$ & $3.69 \pm 0.478$ & $3.50 \pm 0.878$ & -0.19 & .000 \\
\hline & Employees give personal attention & $3.73 \pm 0.447$ & $3.76 \pm 0.509$ & 0.03 & .246 \\
\hline & Personnel have patients' best interests at heart & $3.67 \pm 0.570$ & $3.68 \pm 0.663$ & 0.01 & .780 \\
\hline & Employees understand specific needs & $3.73 \pm 0.447$ & $3.70 \pm 0.573$ & -0.03 & .523 \\
\hline
\end{tabular}


item 20 "Employees give personal attention," and item 21 "Personnel have patient's best interests at heart," the quality gaps were positive. The maximum gaps were found in items $3(-0.78), 4(-0.49)$, and 8 (-0.45). In items $13,16,20$, and 21 , the centers were also assessed positively, with only the gap in item 16 being significant. In items 1 and 12, no gaps were observed between the patients' perceptions and expectations of service quality $(\mathrm{P}-\mathrm{E}=0)$; that is, the patients received the services that they expected.

\section{Discussion}

In this study, the gaps in the quality of rehabilitation services were assessed using the SERVQUAL technique, which is appropriate for evaluating the quality of these services. Generally, the results showed that a patient's expectation of quality was higher (3.73) in all of the dimensions than his/her perception (3.56). Therefore, the quality of services provided by the rehabilitation centers was poor. In addition, the mean score for the patients' perceptions of quality showed that the rehabilitation centers should take fundamental steps toward improving the quality of their services. The studies by Bahadori (8), Vafaee-Najar (16), Aghamolaei (2), Zarei (1), and Ranjbar (17) showed similar results in the hospitals and healthcare centers in Iran, while Lim (18) and Sadiq Sohail (19) showed similar results in other countries.

The highest gaps in this study were in the tangibles (-0.33) and reliability (-0.30), and Vafaee-Najar et al. (16) showed similar results. However, Aghamolaei et al. showed that the gaps in the responsibility and empathy were higher than in the other dimensions (2). In some studies, the gap in the dimension of empathy was the greatest $(1,8)$. The differences in the results of these studies may be due to the research environment, as well as other personal, organizational, and cultural factors affecting the quality of services.

These studies show that private medical centers pay more attention to the physical appearance (tangibles) (20), which emphasizes the appearance of the workplace, medical equipment and facilities, cleanness of the staff, and clean and new furniture in the workplace $(1,2$, 19). The physical appearance of the workplace seems to be important for customers; therefore, hospital managers should provide a clean and beautiful environment for their patients (21). Furthermore, the hotel status and physical appearance of the hospitals and rehabilitation centers have significant impacts on a patient's selection of the center (1); so managers can use new techniques, such as the 5 Smethodology, to improve the quality (22). Reliability is considered to be the vital core of service quality, and the other dimensions will only matter to the customers if the service is reliable (23). Good reliability depends on handling customers' service problems, performing services right the first time, providing services in the promised time frame, and maintaining error-free records $(5,8)$.
Responsibility includes the tendency of personnel to solve patients' problems quickly and easily, the on time delivery of services, providing a clear description of the services to the patients, and reducing patients' waiting times (24). This dimension is oriented more towards the technical dimensions of medical care. Additionally, some studies have shown that reducing a patient's pain in the fastest time possible is part of this dimension (25). The managers of rehabilitation centers can increase the responsibility levels of their centers by providing timely services to increase their patient satisfaction levels (1). Moreover, paying more attention to the patients' rights can strengthen the responsibility dimension $(2,26)$.

According to the results of our study, the gap in the assurance dimension was very low (-0.02), but this gap was not statistically significant. This means that the performances of the rehabilitation centers in this dimension were a bit better than in the others. This dimension refers to being respectful and courteous to the patients, the staff's awareness of new techniques, ensuring the medical skills of the staff, and the sense of safety and security from the medical staff (26). Previous studies have shown that this dimension is more important than the other dimension in the views of the customers (17); therefore, managers can increase their customers' satisfaction by emphasizing techniques that improve service assurance, and creating organizational units to improve the quality (20). The assurance dimension in this study showed that the staff of the rehabilitation centers studied had the requisite knowledge to help the patients, and that their attitudes were courteous, making the patients feel safe and assured. These findings correspond with the results of the study by Zarei et al. (1).

The results of our study also showed that in item 1"Employees are neat in appearance" and item 12 "Personnel are always willing to help," there were no quality gaps; that is, the differences in the perceptions and expectations of the patients were zero. In item 13 "Personnel are never too busy to respond to requests," item 16"Personnel are consistently courteous," item 20"Employees give personal attention, "and item 21 "Personnel have patients' best interests at heart, "the quality gaps were positive, reflecting that the performance of the rehabilitation centers was acceptable, from the point of view of the patients. Therefore, the managers of rehabilitation centers should be more focused on improving the quality of the other items.

There was also a low gap in the empathy dimension (-0.08) shown in our study. Vafaee-Najar et al.(16) showed, in their study, that empathy had the lowest gap, which was similar to our results. However, Zarei et al. (1) and Bahadori et al. (8) reported that empathy had the highest gap when compared to all of the other dimensions. The dimension of empathy includes the personal attention of the staff toward the patients, having affection toward the patients, being sensitive to the feelings of the patients, and keeping the patients' privacy (26). This dimension 
also considers communication techniques. A gap in this dimension indicates poor communication between the patients and the providers (1). Overall, the human factors seemed to have a greater impact on the patients' perceptions of the quality of services than the non-human elements. One of the most important factors in the perception of the quality of services was the interpersonal relationship $(27,28)$. Corresponding to other studies, paying attention to the patients' needs and financial difficulties is defined in this dimension (8).

Reducing the costs of rehabilitation services can improve the perception of the quality of services, because offering cheaper services is one part of the patients' expectations. In this study, the patients stated that, regarding financial costs, the rehabilitation manager must determine reasonable prices to provide quality services. Therefore, one apparent way to improve patient satisfaction in their services is to reduce the costs of these services. However, hospitals may have no desire to reduce their costs. Thus, improving patients' perceptions of the quality of services can be obtained by reducing the nonfinancial costs (reducing waiting times) or increasing the benefits of the services received.

An important component of the empathy dimension is paying attention to the patients' values and emotions, which can have a significant impact on the improvement of their perceptions about the quality of the services provided (16). More empathy from the medical personnel can create more satisfaction in their patients (29). The patients reported staff interest based on the time spent talking and listening to their concerns about anxiety, fear, and stress, and providing them with necessary information about their diseases and treatments to resolve their concerns. However, cultural differences can affect a patient's perspective about the quality of the interactions of the staff.

The results of this study showed a gap between the perceptions of the patients and their expectations of quality rehabilitation services (in the assurance dimension, this gap was very low [negative]). The quality of the rehabilitation services in all of the studied centers and hospitals (except for one public clinic) was lower than the patients' expectations. However, this research did have some limitations. First, the findings were based on the results of selected referral hospitals and rehabilitation centers in Ahvaz city, located in southern Iran; therefore, more studies must be implemented in public and private hospitals to increase the generalizability of the results. Second, in this survey, some of the rehabilitation services, including eudiometry and optometry, were not studied.

\subsection{Conclusion}

The results of this study showed that there were gaps in all of the dimensions of quality in the rehabilitation services, with the exception of the assurance dimension. The tangibles and reliability dimensions had greater gaps than the other dimensions. Additionally, the results showed that the rehabilitation centers have not been able to fully meet the expectations of their patients, and they need to improve the quality of their services. To achieve an acceptable level of quality, it is necessary to apply methods and techniques to improve the quality of rehabilitation services.

\section{Acknowledgments}

This study was the result of an MSc thesis in rehabilitation administration, which was accepted and supported by the research chancellor of the Ahvaz Jundishapur University of Medical Sciences. The authors wish to thank all of the patients in the rehabilitation centers who provided us with their data, and the rehabilitation center personnel for their sincere cooperation.

\section{Footnotes}

Authors' Contribution:Amin Torabipour and Reza Salehi contributed to the study concept and design; Amin Torabipour contributed to the critical revision of the manuscript for important intellectual content, the statistical analysis, administrative, technical, and material support, and study supervision; Amin Torabipour and Rezvan Sayaf analyzed and interpreted the data; Rezvan Sayaf drafted the manuscript and acquisitioned the data; Amin Torabipour, Roya Ghasemzadeh and Reza Salehi edited the manuscript; This manuscript is an original work of the authors, and all of the data, tables, figures, etc. used in the manuscript were prepared originally by the authors. The manuscript has not been and will not be published elsewhere, or submitted elsewhere for publication.

Funding/Support:This study was supported, in part, by a grant (No.PHT-9217) from the research chancellor of the Ahvaz Jundishapur University of Medical Sciences.

\section{References}

1. Zarei A, Arab M, Froushani AR, Rashidian A, Ghazi Tabatabaei SM. Service quality of private hospitals: the Iranian patients' perspective. BMC Health Serv Res. 2012;12:31. doi: 10.1186/1472-6963-12-31. [PubMed: 22299830]

2. Aghamolaei T, Eftekhaari TE, Rafati S, Kahnouji K, Ahangari S, Shahrzad ME, et al. Service quality assessment of a referral hospital in southern Iran with SERVQUAL technique: patients' perspective. BMC Health Serv Res. 2014;14:322. doi:10.1186/1472-6963-14-322. [PubMed: 25064475]

3. Mosadeghrad AM. Factors influencing healthcare service quality. Int J Health Policy Manag. 2014;3(2):77-89. doi: 10.15171/ ijhpm.2014.65. [PubMed: 25114946]

4. Mosadeghrad AM. A conceptual framework for quality of care. Mater Sociomed. 2012;24(4):251-61. doi: 10.5455/msm.2012.24.251261. [PubMed: 23922534]

5. Nekoei-Moghadam M, Amiresmaili M. Hospital services quality assessment: hospitals of Kerman University of Medical Sciences, as a tangible example of a developing country. Int J Health Care Qual Assur. 2011;24(1):57-66. doi: 10.1108/09526861111098247. [PubMed: 21456498]

6. Peersman W, Jacobs N, De Maeseneer J, Seuntjens L. The Flemish version of a new European standardised outcome instrument 
for measuring patients' assessment of the quality of care in general practice. Arch Public Health. 2002;60:39-58.

7. Verbeek J, van Dijk F, Rasanen K, Piirainen H, Kankaanpaa E, Hulshof C. Consumer satisfaction with occupational health services: should it be measured? Occup Environ Med. 2001;58(4):2728. [PubMed: 11245745]

8. Bahadori M, Raadabadi M, Heidari Jamebozorgi M, Salesi M, Ravangard R. Measuring the quality of provided services for patients with chronic kidney disease. Nephrourol Mon. 2014;6(5):e21810. doi:10.5812/numonthly.21810. [PubMed: 25695038]

9. Medina-Mirapeix F, Del Bano-Aledo ME, Oliveira-Sousa SL, Escolar-Reina P, Collins SM. How the rehabilitation environment influences patient perception of service quality: a qualitative study. Arch Phys Med Rehabil. 2013;94(6):1112-7. doi: 10.1016/j. apmr.2012.11.007. [PubMed:23154133]

10. Cuesta-Vargas AI, Gonzalez-Sanchez M. Changes in disability, physical/mental health states and quality of life during an 8-week multimodal physiotherapy programme in patients with chronic non-specific neck pain: a prospective cohort study. PLoS One. 2015;10(2):e0118395. doi: 10.1371/journal.pone.0118395. [PubMed: 25710539]

11. Fitts SS, Guthrie MR, Blagg CR. Exercise coaching and rehabilitation counseling improve quality of life for predialysis and dialysis patients. Nephron. 1999;82(2):115-21. doi: 10.1159/000045386. [PubMed:10364702]

12. Lin DJ, Sheu IC, Pai JY, Bair A, Hung CY, Yeh YH, et al. Measuring patient's expectation and the perception of quality in LASIK services. Health Qual Life Outcomes. 2009;7:63. doi: 10.1186/1477-75257-63. [PubMed:19591682]

13. Curry A, Sinclair E. Assessing the quality of physiotherapy services using SERVQUAL. Int J Health Care QualAssur. 2002;15(5):197205. doi:10.1108/09526860210437412.

14. Pena MM, da Silva EM, Tronchin DM, Melleiro MM. [The use of the quality model of Parasuraman, Zeithaml and Berry in health services]. Rev Esc Enferm USP. 2013;47(5):1235-40. doi:10.1590/S0080623420130000500030. [PubMed: 24346466]

15. Taner T, Antony J. Comparing public and private hospital care service quality in Turkey. Int J Health Care Qual Assur Inc Leadersh Health Serv. 2006;19(2-3):i-x. [PubMed:16875104]

16. Vafaee-Najar A, Nejatzadegan Z, Pourtaleb A, Kaffashi S, Vejdani M, Molavi-Taleghani Y, et al. The quality assessment of family physician service in rural regions, Northeast of Iran in 2012. Int J Health Policy Manag. 2014;2(3):137-42. doi:10.15171/ijhpm.2014.35.
[PubMed: 24757691]

17. Ranjbar Ezatabadi M, Bahrami M, ZareAhmadabadi H, Arab M Nasiri SH. Analysis of SERVQUAL in ShahidSadoghi Hospital, Yazd, Iran. Hormozgan Med J. 2012;16(4):333-40.

18. Lim PC, Tang NK. A study of patients' expectations and satisfaction in Singapore hospitals. Int J Health Care Qual Assur Inc Leadersh Health Serv. 2000;13(6-7):290-9. [PubMed:11484647]

19. Sadiq Sohail M. Service quality in hospitals: more favourable than you might think. Manag Serv Qual Int Journal. 2003;13(3):197-206. doi: $10.1108 / 09604520310476463$.

20. Butt MM, de Run EC. Private healthcare quality: applying a SERVQUAL model. Int J Health Care Qual Assur. 2010;23(7):658-73. doi:10.1108/09526861011071580. [PubMed: 21125961]

21. Andaleeb SS. Service quality perceptions and patient satisfaction: a study of hospitals in a developing country. Soc Sci Med. 2001;52(9):1359-70. [PubMed: 11286361]

22. Young FY. The Use of 5S in Healthcare Services: a Literature Review. Int J Bus Soc Sci. 2014;5(10):240-8.

23. Quality Dimensions and Customers' Satisfactions of Banks in Egypt. In: El Saghier N, Nathan. Proceedings of 20th International Business Research Conference. 2013 Dubai.

24. Parasuraman A, Zeithaml VA, Berry LL. A Conceptual Model of Service Quality and Its Implications for Futuring Research. $J$ Mark. 1985;49:41-50. doi:10.2307/1251430.

25. Merkouris A, Papathanassoglou ED, Lemonidou C. Evaluation of patient satisfaction with nursing care: quantitative or qualitative approach? Int J Nurs Stud. 2004;41(4):355-67. doi: 10.1016/j. ijnurstu.2003.10.006. [PubMed:15050847]

26. Garrard F, Narayan H. Assessing obstetric patient experience: a SERVQUAL questionnaire. Int JHealth Care QualAssur. 2013;26(7):58292. doi:10.1108/IJHCQA-08-2011-0049. [PubMed: 24167918]

27. Mohd Suki N, Chwee Lian JC, Suki NM. A comparison of human elements and nonhuman elements in private health care settings: customers' perceptions and expectations.J Hosp Mark Public Relations. 2009;19(2):113-28. doi: 10.1080/15390940903041567. [PubMed:19827322]

28. Rose RC, Uli J, Abdul M, Ng KL. Hospital service quality: a managerial challenge. Int J Health Care Qual Assur Inc Leadersh Health Serv. 2004;17(2-3):146-59. [PubMed:15301271]

29. Szyca R, Rosiek A, Nowakowska U, Leksowski K. Analysis of factors influencing patient satisfaction with hospital treatment at the surgical department. Pol Przegl Chir. 2012;84(3):136-43. doi: 10.2478/v10035-012-0022-3. [PubMed: 22659356] 